\title{
Gastric Bypass and Cardiac Autonomic Activity: Reply for the Letter of Russo et al.
}

\author{
Marcos Borges Machado • Irineu T. Velasco • \\ Augusto Scalabrini-Neto
}

Received: 18 November 2008 / Accepted: 20 November 2008/Published online: 10 December 2008

(C) Springer Science + Business Media, LLC 2008

To the Editor:

First, we would like to thank Dr. Russo for his comments.

In his letter, he states that our work confirms the results of previous reports in smaller groups of patients and comments about our selection criteria of obesity patients.

Although we really did not include in the exclusion criteria the presence of respiratory disturbances, there was in our group just one patient with history of chronic pneumopathy. The others have no diagnosis of respiratory diseases.

We described in our paper that the number of patients with antihypertensive drugs decreased from 25 to six patients 6 months after surgery. In his letter, Russo comments the absence of information about angiotensinconverting enzyme inhibitors (ACE inhibitors) and angiotensin II receptors blockers (ARBs), others drugs (steroid hormones, antidepressants, appetite suppressants), and smoking. In fact, we found in our group ten patients using $\mathrm{ACE}$ inhibitors before surgery and just one patient 6 months after surgery. Three patients were using ARBs before and none after. There were no patients using sex steroid hormones or appetite suppressants. No patient was using antidepressants before surgery and just one patient was using after (fluoxetine). Six patients were smokers before surgery and two patients stopped smoking after it.

We did not consider, in our report, the fertility state of the women. The postmenopausal women are older than the premenopausal women. The age can influence the absence of statistical difference of heart rate variability between lean and obese groups in postmenopausal age observed in the report of Monda et al. [1]. The values of heart rate variability measures decrease with the aging process for women and men [2].

We are glad to know that the preliminary data of Russo et al. are in accordance with our results. Thus, we think that the aspects commented on about our selection criteria did not have any influence over the results.

\section{References}

1. Monda M, Messina G, Vicidomini C, et al. Activity of autonomic nervous system is related to body weight in pre-menopausal, but not in post-menopausal women. Nutr Neurosci. 2006;9(3-4):141-5.

2. Antelmi I, de Paula RS, Shinzato AR, et al. Influence of age, gender, body mass index, and functional capacity on heart rate variability in a cohort of subjects without heart disease. Am J Cardiol. 2004;93(3):381-5.

M. B. Machado $(\square)$

Department of Medicine, State University of Maringá,

Av Independência, 258, Sala 2,

Maringá, PR 87060-230, Brazil

e-mail: mbmachado@wnet.com.br

I. T. Velasco $\cdot$ A. Scalabrini-Neto

Department of Emergency Medicine, School of Medicine,

University of São Paulo,

São Paulo, Brazil 